\title{
SETTING AN INDUSTRY 4.0 RESEARCH AND DEVELOPMENT AGENDA FOR SIMULATION - A LITERATURE REVIEW
}

\author{
Vieira, A. A. C.; Dias, L. M. S.; Santos, M. Y.; Pereira, G. A. B. \& Oliveira, J. A. \\ University of Minho, Campus Gualtar, 4710-057, Braga, Portugal \\ E-Mail: antonio.vieira@dps.uminho.pt,1sd@dps.uminho.pt,maribel@dsi.uminho.pt, \\ gui@dps.uminho.pt, zan@dps.uminho.pt
}

\begin{abstract}
The fourth industrial revolution, or Industry 4.0 (I4.0), originated in German, englobes many innovative features, in order to bring the concept of "smart factories". Moreover, discrete-event simulation (DES) is one of the most important areas involved in this goal. With this in mind, the purpose of this paper is to propose a research and development agenda (R\&D) for DES researchers and practitioners, in order to comply with the I4.0 agenda. To achieve this, a literature review (LR) was conducted, in which 45 papers were considered relevant for this research. From their analysis, it was found that: the ability to automatically generate simulation models; the automation of data exchange between manufacturing applications and simulation tools; and visualization features, are the most essential DES features for I4.0. Thereafter, the LR focused on analysing the most recent papers in these areas of simulation, in order to propose a list of R\&D items for DES researchers and practitioners.

(Received in August 2017, accepted in June 2018. This paper was with the authors 2 months for 3 revisions.)
\end{abstract}

Key Words: Discrete-Event Simulation, Industry 4.0, Visualization, Data Exchange Automation, Automatic Generation, Research and Development, Literature Review

\section{INTRODUCTION}

Since its beginnings, industry has suffered several paradigm shifts, which are labelled as industrial revolutions [1]. The first occurred when water, steam power and mechanics started to become standardized, in the end of the $18^{\text {th }}$ century. The second emerged with the use of electricity, which enabled the advent of concepts such as mass production, at the beginning of the $20^{\text {th }}$ century. Later, around the 1970 s, came the digital era and computers, which triggered the shift to the third industrial era, which is, in fact, arguably still ongoing, as the transition originated by the fourth industrial revolution is not yet complete.

Ultimately, industry will enter its fourth era and hence the term "Industry 4.0" (I4.0). The term originated from the German expression "Industrie 4.0", which become known in 2011, when an association of the same name promoted an idea aiming towards the enhancement the competitiveness of the German manufacturing industry. In its turn, the German government supported this, by announcing that Industrie 4.0 would be part of its "High-Tech Strategy 2020 for Germany" initiative, aiming at technological innovation leadership [2]. Thereafter, the term was adopted in Europe as "Industry 4.0" [1]. Despite this, other zones of the globe also adopted their own projects, focusing on technological innovation, e.g. United States and Chine. Notwithstanding, the German program is the one with most capital investment [3].

I4.0 encloses several technological concepts, such as interoperability among different systems, semantics between machines, decentralization, cyber-physical systems, virtualization, automation and others. By implementing these concepts, it is expected that the smart factory will be a reality $[1,2]$. Several fields of knowledge can contribute to this end, such as: robotics, materials, information, informatics, manufacturing among other fields, including Discrete-Event Simulation (DES), which can play a very relevant role [2, 4].

DES is a technique that is used to run models that represent systems being analysed, with different types of objectives and the literature on studies using it is vast [5-7]. In fact, 
according to Jahangirian et al. [8], simulation is the second most widely used technique to deal with operations management in manufacturing and business processes. Its application may go from internal logistics problems $[9,10]$ to production lines [11], among others. As can be seen, DES is a solid technique with many years of application and has tackled many different problems.

Some of the main benefits associated to DES include: the ability to simulate years of a real system in a much shorter time; ability to study different components of a system and their interactions; better understanding of the system in analysis, benefiting all stakeholders involved; study alternatives without incurring in unnecessary risks, costs and danger; monitor and control the system, solving complex problems, decision-making, and others $[12,13]$. To perform these simulation studies, typically, commercial tools are used, with many options on the market, e.g., Simio, PlantSimulation, FlexSim. In this regard, several studies exist that compare DES tools taking into account different factors [14-16].

Despite the current knowledge regarding DES, with the growing importance that is currently given to information virtualization, systems interoperability, knowledge extraction from Big Data sets and other highly technological concepts, it becomes mandatory to understand what are the types of problems in which DES can be used that require further contributes, in order for DES to comply with the I4.0 agenda. Thus, the purpose of this paper is to identify these types of problems, by proposing a research and development (R\&D) agenda for DES practitioners and researchers. In this sense, this R\&D agenda is supported in a literature review (LR), aiming to identify the current contributes of DES to I4.0 and to identify gaps in literature.

To the best of the author's knowledge, this is the first paper that tries to propose a list of R\&D items that need further contributes, in order for DES to comply with I4.0. In fact, searching the Scopus database for ["simulation" AND ( "industry 4.0" OR "industrie 4.0" ) AND "literature review"] only returns 1 result [3], as of December of 2017. Next section focuses on discussing the research design followed in this study and section 3 focuses on discussing the LR. For this purpose, two research questions (RQs) were formulated; hence, section 3 is divided in two subsections, one for each RQ. Literature gaps were identified, which allowed the authors to formulate a $R \& D$ agenda, which is addressed in the fourth section. Finally, the last section addresses the main conclusions of this study.

\section{RESEARCH DESIGN}

\subsection{Research objective and questions}

In this section, the research design followed by this study is discussed. As already stated, the research objective (RO) of this study was defined as:

- Research objective: to identify what are the problems related to DES, within the I4.0 agenda, that need further contributes, by proposing a R\&D agenda.

To achieve this goal, a LR was conducted. In this sense, the RO was decomposed in two research questions (RQ). The first RQ was formulated in the following way:

RQ1: What are the main DES features that should contribute to the I4.0 agenda?

As the formulation of the question suggests, answering it, it is necessary to find papers that specifically state in what aspects DES can contribute to the I4.0 agenda. However, to find the proper answer to this RQ, identifying what these aspects are is not enough, as it is necessary to delve deeper into the matter. Therefore, the authors formulated a second RQ:

RQ2: What are the current solutions related to the DES features identified in RQ1?

Apart from allowing finding the current contributes of DES to I4.0, this RQ also allows to identify gaps of important problems not properly addressed by the DES community. After answering RQ2, a proper R\&D agenda can be set. Figure 1 depicts the drawn research design. 


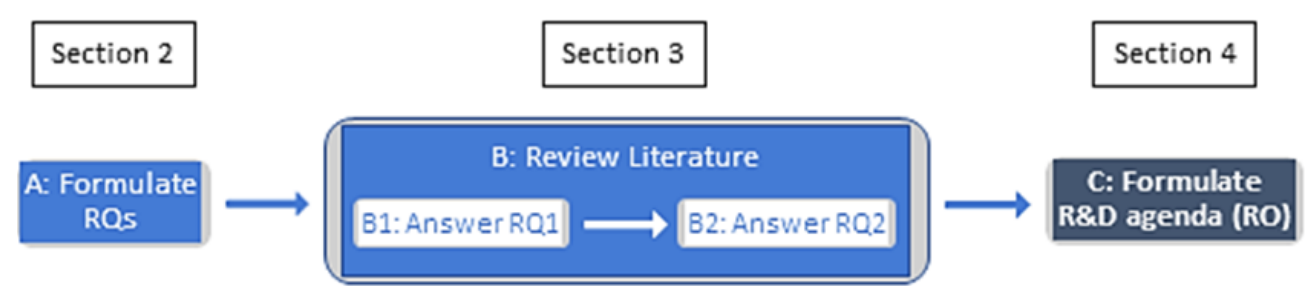

Figure 1: Research design used in this study.

The research followed in this paper starts by formulating RQs (phase A), followed by the literature review process (phase B). In this phase, RQ1 must be answered before RQ2, meaning that search queries for RQ2 can only be defined after answering RQ1. To perform the LR (step B), for each RQ, a search process was performed, which is explained in next subsection. After the literature review finishes, a proper R\&D agenda can be set (phase C).

\subsection{Search process}

The search process followed to find relevant papers for both RQs is depicted in Figure 2.

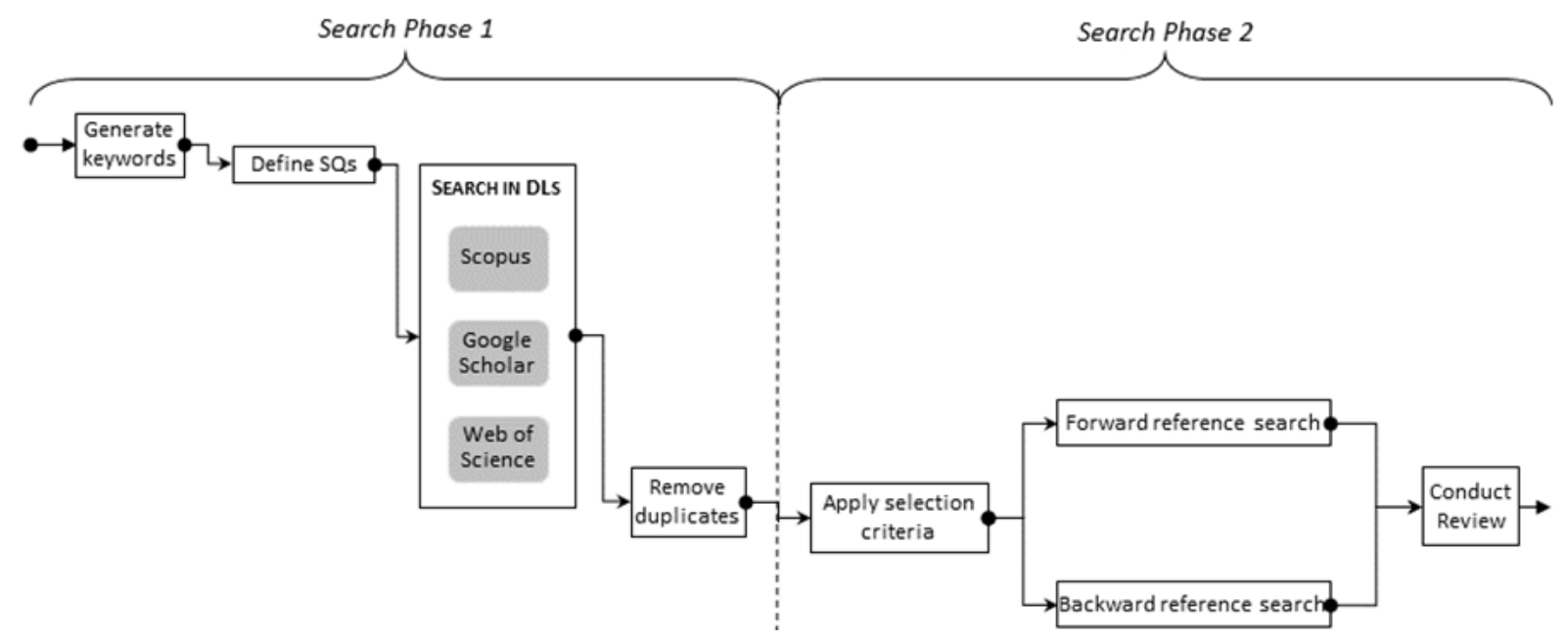

Figure 2: Diagram of search process.

i. $\quad$ Search Phase 1

The search process starts with the keywords definition phase. Since RQ1 centres on DES and I4.0, two sets of keywords related to these topics were used. Regarding DES, using just the keyword "simulation" would result in a great percentage of papers not relevant to the study in question, since many techniques can be labelled as such, as indicated by Jahangirian et al. [8]. On the other hand, disregarding this possibility would result in excluding some authors who do not specify the DES technique and use just "simulation". Thus, the search query definition took this into consideration, by including the names of some tools, to filter results retrieved by the keyword "simulation", which are not related to DES. The main consulted digital libraries were Scopus, Google Scholar and Web of Science. It should be noted that only papers published after 2011 were considered, since the concept of I4.0 emerged in this year $[1,2]$.

ii. $\quad$ Search Phase 2

After obtaining a set of papers, selection criteria were applied to determine which papers were relevant for each RQ. Thus, the following exclusion criteria were applied to exclude papers: paper is not written in English; paper is non-academic; and paper does not contribute with specific answers to the formulated RQs. With the set of included papers, the search continued, by performing backward reference search (search papers in the references of relevant papers) and forward reference search (search papers that referenced the relevant papers). 


\section{LITERATURE REVIEW}

The results obtained for each of the formulated RQs will be discussed in this section, which is divided in two subsections, one for each RQ.

\subsection{What are the main DES features that should contribute to the I4.0 agenda?}

I4.0 is a collective term that embraces a number of concepts, as given by Lasi et al. [1]. The integration of the physical world and its virtual copy in the cyberspace, through CPS (CyberPhysical Systems), the IoT (Internet of Things) and IoS (Internet of Services) with the goal of reaching a "smart factory". I4.0 is, thus, a goal and to achieve it, some of the steps that must be taken are: a paradigm shift from centralized to decentralized, modularity, interoperability between different systems, semantics between machines and information virtualization [1].

According to Lasi et al. [1], the main triggers that can be identified for the rise of I4.0 are: the need for a decrease in development and innovation periods and the chase for product customization. Ensuring this demands higher resource efficiency, flexibility and decentralizations. On the other hand, the authors also stressed some of the expected technology advancements. Firstly, the increase in use of mechanization and automation in several industrial processes. Secondly, advancements in the digitalization are also expected, since large amounts of data are being retrieved form manufacturing- tools and can support functions of control and analysis that need to be explored. Lastly, the authors also emphasized the role of miniaturization, due to the expansion of embedded and ubiquitous computing.

I4.0 requires different knowledge areas to develop the afore-mentioned steps. One of such areas is DES [17]. In fact, Brettel et al. [17] and Posada et al. [18] emphasized the need to virtualize and visualize supply chain networks. Similarly, Turner et al. [4] focused on the benefits that VR can bring to DES projects, as an essential aspect to enable the visualization of smart factory operations, easing the validation process. In fact, according to Chong et al. [3], VR will be the key technology for the factories of the future. The need for visualization features of DES solutions to be used in I4.0 is shared by other authors [1, 2, 19].

Turner et al. [4] also discussed about the importance of real-time DES, particularly in linking to Big Data sets, which is corroborated by Kagermann et al. [2], who further stressed the ability to model and visualize complex supply chain networks. Furthermore, the authors also mentioned the need to interact with real physical objects, creating a model, which overlaps reality data and simulation data in real-time. Turner et al. [4] also suggested that DES solutions should be able to help decision-makers reach optimum solutions of problems and automatically apply them in the field, by communicating with the required systems, or machines. The need for data exchange capabilities is also indicated by Lasi et al. [1] and Ferro et al. [19].

In summary, by analysing literature related to I4.0, it becomes evident that DES solutions should contribute to the industrial revolution, by primarily focusing in the following aspects:

- Automated data exchange: Receiving real data from real objects (e.g. machines, sensors and others) and automatically insert it into the simulation model. This is of greater importance since these data generators produce data at increasing rates;

- Automatic model generation: The ability to automatically build simulation models. In the context of I4.0 where factories are very dynamic, the systems being modelled may require frequent changes, which must be met by modellers, in a fast and effortless way;

- Visualization: The ability to visualize complex systems, through the ability to immerse users in a virtual reality environment, or integration with augmented reality.

From the reviewed literature, the real-time keyword is mostly associated to the ability of automated data input into the simulation model. On the other hand, there are also some authors that consider the real-time keyword to englobe not only automated data exchange, but 
also the ability to automatically generate simulation models, as is the case of Fowler and Rose [12]. Table I shows the list of DES features mentioned by each of the reviewed studies.

Table I: Highlighted DES features for I4.0 per reviewed paper of RQ1.

\begin{tabular}{|l|c|c|c|}
\hline Authors [reference] & Data exchange & Model generation & Visualization \\
\hline Lasi et al. [1] & $\checkmark$ & & $\checkmark$ \\
\hline Kagermann et al. [2] & $\checkmark$ & $\checkmark$ & $\checkmark$ \\
\hline Turner et al. [4] & $\checkmark$ & $\checkmark$ & $\checkmark$ \\
\hline Brettel et al. [17] & & & $\checkmark$ \\
\hline Posada et al. [18] & & & $\checkmark$ \\
\hline Ferro et al. [19] & $\checkmark$ & & $\checkmark$ \\
\hline
\end{tabular}

From the above table, it is possible to verify that all studies mention visualization of processes. It is interesting to note, however, that for some practitioners, the importance of animation in DES is still arguable. In their study, Akpan et al. [20,21] assessed these claims. Moreover, the keyword visualization englobes others, such as: virtualization, augmented reality, virtual reality and 3D. Thus, it is also important to include these in the search for papers. From the remaining aspects (data exchange and model generation), these needs had already been suggested by other authors, such as Robinson [22], Fowler and Rose [12] and Hollocks [23]. Fowler and Rose [12] identified what, in their opinion, were the grand challenges for DES. According to them, grand challenges are those that are difficult, probably solvable and its solution should contribute to a significant impact to the community. The authors propose an alternative way to automatic generate simulation models, which consists in developing sets of submodels that can be shared by modellers and connected to form simulation models. According to Hollocks [23], since the earliest days of simulation, there was an interest in creating the means to make modelling more rapid and more reliable. Initially, this led to the creation of simulation languages, which was followed, as a natural continuation, by generators.

\subsection{What are the current solutions related to the DES features identified in RQ1?}

From the answers to RQ1, it was possible to define 3 new search queries to answer RQ2, for visualization, data exchange automation and generation of DES models.

i. $\quad$ Visualization in DES

Akpan and Brooks [24] stated some of the main benefits of visualization in DES, including: achieving new insights in system analysis, better modelling, validation, communication with stakeholders, and others. Motivated by the lack of empirical evidence showing the benefits of 3D animation over 2D, Akpan and Brooks [25] wanted to verify if the performance of modellers can be influenced by the type of animation used, i.e., 2D or 3D. The authors conducted experiments to verify if these types of displays could influence users, namely in: spotting errors, understanding of the system, generation of ideas for improving the system and model acceptability. From these, the authors concluded that indeed 3D animation could enhance all but the ability to generate ideas for improving the system, albeit the authors emphasize this could be due to the complexity of the system used in the experiment, since it was very simple. The authors also considered that there is a lack of empirical evidence suggesting the analysis of 3D models decreases when models are too complex or too large and that the improvement of model acceptability with 3D displays is independent of model complexity or size [25].

In a posterior survey, the same authors [24] assessed the main benefits and drawbacks of $2 \mathrm{D}$ and $3 \mathrm{D}$ animation. The authors concluded that the main drawback of 3D displays is the increase in time of the model building phase. The main benefits were very similar to the 
general advantages of animation, regardless of the type of display and to those reported in the posterior study [25]. This indicates that 3D enhances the general benefits of $2 \mathrm{D}$ animations [24].

Another type of animation starting to receive attention from DES modellers and hence from some DES commercial tools is the ability to merge VR (Virtual Reality) in DES models. Turner et al. [4] analysed literature around this topic and pondered about the role that simulation will have in I4.0, while providing a discussion about the main benefits and drawbacks of VR DES. Whilst most advantages enhance the potential advantages that could be achieved with 3D animation, some of its limitations include the high monetary and computational costs involved and the additional expertise required to use this technology. According to them, VR will inevitably become the main form of animation in DES, albeit at the moment the technology still must mature and production costs to decrease, albeit it is expected that this technology will be able to further improve the benefits of 3D animation. Examples of DES models implemented in VR environments was provided by Ghani et al. [26], Petti et al. [27] and Oyekan et al. [28].

Bijl et al. [21] presented a 3D visualization tool which employs game technology for graphics visualization in DES models. The authors compared the animation performance of their tool with the animation features of other well-known DES tools, namely: AnyLogic, Arena, Simio, FlexSim and Enterprise Dynamics. Interestingly, the authors considered that DES tools vendors have the available technology to considerably improve the animation capabilities of their software, albeit they are still somewhat sceptical about their relevance.

Akpan and Shanker [20] synthesized some of the potential benefits and costs associated with modelling and simulation in 3D and VR. Moreover, the authors conducted a literature review of existing evidence of the influence of 3D and VR in DES. They concluded that, indeed, 3D and VR improve several tasks in simulation modelling and debunked some of the existing in this regard. Table II shows the type of visualization considered by the reviewed papers.

Table II: DES visualization types analysed by reviewed papers.

\begin{tabular}{|l|c|c|c|}
\hline \multicolumn{1}{|c|}{ Authors [reference] } & 3D & AR & VR \\
\hline Akpan and Shanker [20] & $\checkmark$ & & $\checkmark$ \\
\hline Bijl and Boer [21] & $\checkmark$ & & \\
\hline Akpan and Brooks [24] & $\checkmark$ & & \\
\hline Akpan and Brooks [25] & $\checkmark$ & & \\
\hline Ghani et al. [26] & & & $\checkmark$ \\
\hline Petti et al. [27] & $\checkmark$ & & $\checkmark$ \\
\hline Oyekan et al. [28] & & & $\checkmark$ \\
\hline
\end{tabular}

As the nad table shows, all reviewed papers considered either 3D visualization or VR in their studies. On the other hand, none of the reviewed studies considered AR.

ii. $\quad$ Automated data exchange and model generation in DES

Data input in DES is considered the most critical and time-consuming phase in DES projects, ranging from 40 to $50 \%[13,29,30]$. Input data management, according to Skoogh et al. [29], includes around $80 \%$ of manual involvement, due to lack of interoperability between applications. A broad description of the main problems related to data input was given by Skoogh et al. [29]. Some of these examples include: low quality data, difficulty in identifying available data sources and others. Because of this, Jahangirian et al. [8] verified that half of the analysed studies did not use real data, which could result in a reduced stakeholders' interest. Skoogh et al. [29] considered 4 different types of data input and labelled them as following: 
- Methodology A - Data is entered manually;

- Methodology B - Data is manually entered in spreadsheets;

- Methodology C - Data is automatically stored in intermediary data sources; and

- Methodology D - Direct link to data sources.

The first consists on manually entering data. This type of input also requires data to be processed and analysed, which is time-consuming, since the destinations for these data can be spread across different parts of the simulation model. Furthermore, data usually comes from more than 1 data source. This enhances problems related with mistyped input values.

Methodology B uses computer applications, or manually populated external data sources. Whilst this overcomes some of the problems with the first method, since data is now centralized in a separate application (e.g. Excel spreadsheet), the modeller still must perform the data collection phase. This is still the most popular method and used by $80 \%$ of the participants in the survey of Skoogh et al. [29]. Rodriguez [31] developed the DESI interface for data collection for DES models. According to the author, the solution can be used on any area of application, not being limited to manufacturing, for instance, albeit the author agrees that the manual interaction required to collect data into the tool is a drawback. The tool was tested, by inputting data into an Arena model. Vieira et al. [9, 32] used MS Excel spreadsheets to input data into automatically generated simulation models of warehouse systems. The developed generator is applicable to Simio and was demonstrated in a case study. Krenczyk [33] used data imported to XML files and used it to automatically generate simulation models in Enterprise Dynamics. According to the author, the developed tool can be used in different DES software.

Methodology $\mathrm{C}$ is an automatic version of the previous method, with this being typically achieved by using external databases. Lastly, the fourth data entry method consists on eliminating the need for this external data storage and creates a direct link between the simulation model and an external data source, e.g. ERP (Enterprise Resource Planning). This also consist one of the grand challenges for DES in the vision of Fowler and Rose [12]. The major blockers for the adoption of this method are the lack of interoperability between the data source and the simulation models, as well as the lack of information required being stored in these external data sources. Skoogh et al. [29] considered that the external database used in the $\mathrm{C}$ methodology could be used for security reasons, avoiding the assuring that interoperability problems do not affect the shared data. An equivalent classification to the afore-mentioned methodologies for data input was given by Robertson and Perera [34, 35].

In its turn, after reviewing related literature, Barlas and Heavey [30] proposed the following classification of ways to automate data input for DES:

- Methodology 1 - Data is automatically stored in intermediary data sources;

- Methodology 2 - Data is automatically retrieved from PLC code;

- Methodology 3 - Data is automatically retrieved by developed applications

- Methodology 4 - Standards to automate data interchanges;

- Methodology 5 - Direct integration between DES model and data sources.

The first consists on using automatically updated external data sources, similarly to the C methodology of Robertson and Perera [34, 35] and Skoogh et al. [29]. Dias et al. [10] proposed a tool for automatic generation of simulation models of alternative scenarios, in Witness, aiming to optimize different types of processes and layouts. The tool retrieves data from a database, which, in its turn, retrieves information from spreadsheets, or even other systems, e.g. ERP. The tool was tested in a case study. Another example was provided by Barlas et al. [36].

The second consists on using PLCs (Programmable Logic Controller), which are digital computers that are widely used to control manufacturing processes. In a PLC, several types of data can be stored, e.g. machines layout. Popovics et al. [37-39] used data obtained from PLC 
to obtain data and control logic, in order to automatically build the DES model representation. It should be noted that this solution in only applied to data originated from low-level controllers, e.g. machines in production line.

The third method proposed by Barlas and Heavey [30] consists on using developed applications, which are used for several purposes, such as: distribution fitting purposes. Skoogh et al. [40] presented GDM-Tool, which automates several critical and timeconsuming phases of data collection in DES projects, namely: transformation of raw data to simulation data, calculations and distribution fitting. The developed application retrieves the required data from several data sources, transforms it into simulation data and stores it in a database. The authors used a case study to validate their proposal, claiming to have achieved a time reduction of $78 \%$. Another developed application is KE (Knowledge Extraction) tool, presented by Barlas et al. [41], which extracts data from several data sources of organizations, analyses it and outputs it in a format that is applicable to DES tools. To note that this is all conducted in one automated process. The authors tested the tool in a case study of a production line. In its turn, Haraszkó and Németh [42] also developed an automatic simulation model generator in Plant Simulation. The input data could be manually entered or the user could connect it to a database. Lastly, Popovics et al. [13] proposed EasySim, a framework for automatically building DES models, which applied the ISA-95 standard for data input and output between the simulation model and data sources, which could be Excel files, databases or XML files. The proposed framework also includes validation methods, which consists on statistically comparing the results obtained by simulation runs with the ones provided by the data interfaces. The authors also tested the framework with experiments with job shop models in the Plant Simulation and in the proposed framework.

In its turn, the fourth consists on using interoperable data interfaces or translators between the simulation model and manufacturing applications. These interfaces use standards to interchange data between applications. Lee et al. [43] compared different data exchange interface standards, such as CMSD, OAGIS (Open Applications Group Integration Specification), ISA-95 (Instrumentation, Systems, and Automation Society) and others. Bloomfield et al. [44] implemented a solution of this kind, which generates a DES model of a production line in ProModel. The authors tested the solution in two case studies. The first, aimed to automatically generate the intended DES models from data of the production assembly and the second considered the data interoperability between the translator and the DES application. The authors developed a translator to allow an interoperable data exchange between a DES software tool and a manufacturing system, storing relevant data for the DES model. The translator uses an XML file to extract relevant data from the manufacturing system and then a schema to parse the retrieved information to the required format, allowing the interpretation of the data by the receiver DES tool. This translator contains programming code that is used to automatically build part of the intended simulation model with all the required parameters, e.g. processing time and sequence, resource information and others. The authors considered that the main benefits from this solution were the decreased time to develop the DES model, the elimination of human error in data input and the introduction of process time variation. In its turn, Lee et al. [43] presented a case study, in which the CMSD was used to exchange data with job shop DES models created in Enterprise Dynamics, Plant Simulation and Arena.

Lastly, the fifth method, as proposed by Barlas and Heavey [30], consists on a direct integration of the simulation model within the data sources (e.g. ERP, MES), thus eliminating the need for an intermediate data source, or any intermediary artefact. In this methodology, the DES model is directly linked to relevant data sources, enabling real-time reconfiguration and re-run simulations with up-to date data, without effort. According to Barlas et al. [30], only $3 \%$ of the participants in their survey implemented this approach, albeit $38 \%$ stated 
their wish to apply this approach in the next 10 years. Kirchhof [11] developed, in Simio, a fully automatic production line DES model generator with full integration with ERP and MES. However, little information regarding this is provided by the author. Table III shows the list of papers relevant to answer RQ2, regarding data input automation and generation of DES model.

Table III: Information of relevant papers for data automation and generations of simulation models.

\begin{tabular}{|c|c|c|c|c|c|}
\hline \multirow[b]{2}{*}{ Authors [ref.] } & \multicolumn{2}{|c|}{ Data input method } & \multirow[b]{2}{*}{$\begin{array}{l}\text { Automatic } \\
\text { generation }\end{array}$} & \multirow[b]{2}{*}{$\begin{array}{l}\text { Problem } \\
\text { domain }\end{array}$} & \multirow[b]{2}{*}{$\begin{array}{l}\text { Simulation } \\
\text { tools used }\end{array}$} \\
\hline & $\begin{array}{l}\text { Skoogh et } \\
\text { al. [29] }\end{array}$ & $\begin{array}{c}\text { Barlas and } \\
\text { Heavey } \\
\text { method [30] }\end{array}$ & & & \\
\hline Vieira et al. [9] & B & NA & Yes & Internal logistics & Simio \\
\hline Dias et al. [10] & $\mathrm{C}$ & 1 & Yes & Internal logistics & Witness \\
\hline Kirchhof [11] & $\mathrm{D}$ & 5 & Yes & Production & Simio \\
\hline Popovics et al. [13] & $\mathrm{C}$ & 3 & Yes & Production & $\begin{array}{l}\text { Plant Simulation } \\
\text { EasySim }\end{array}$ \\
\hline Vieira et al. [32] & B & NA & Yes & Internal logistics & Simio \\
\hline Krenczyk [33] & B & NA & Yes & Production & $\begin{array}{l}\text { Enterprise } \\
\text { Dynamics }\end{array}$ \\
\hline Popovics et al. [37] & $\mathrm{D}$ & 2 & Yes & Production & Plant Simulation \\
\hline Popovics et al. [38] & $\mathrm{D}$ & 2 & Yes & Production & Plant Simulation \\
\hline Popovics et al. [39] & $\mathrm{D}$ & 2 & Yes & Production & Plant Simulation \\
\hline $\begin{array}{l}\text { Haraszkó and Németh } \\
\text { [42] }\end{array}$ & $\mathrm{C}$ & 3 & Yes & Production & Plant Simulation \\
\hline Bloomfield et al. [44] & $\mathrm{D}$ & 4 & Yes & Production & ProModel \\
\hline Rodriguez [31] & B & NA & No & Several & Arena \\
\hline Barlas et al. [36] & $\mathrm{C}$ & 3 & No & Production & ManPy \\
\hline Skoogh et al. [40] & $\mathrm{C}$ & 3 & No & Production & $\begin{array}{l}\text { Enterprise } \\
\text { Dynamics }\end{array}$ \\
\hline Barlas and Heavey [41] & $\mathrm{C}$ & 3 & No & Production & ManPy \\
\hline Lee et al. [43] & $\mathrm{D}$ & 4 & No & Production & $\begin{array}{l}\text { Enterprise } \\
\text { Dynamics } \\
\text { Plant Simulation } \\
\text { Arena }\end{array}$ \\
\hline Skoogh et al. [29] & NA & NA & NA & & \\
\hline Barlas and Heavey [30] & NA & NA & NA & & \\
\hline
\end{tabular}

The first thing to note is that from the 18 reviewed papers, only 2 did not present a solution, but rather performed a review and a survey. From the solutions set, it is interesting to see that 3 solutions regard systems related to internal logistics $(19 \%)$ and the remaining focus on job shop systems $(81 \%)$. Moreover, only 4 studies used middleware applications (e.g. MS Excel) to provide data to the simulation model. The remaining solutions used some type of direct link between model and data sources, regardless of which method it was [29, 30]. Regarding these methods of direct integration, it is possible to verify that developed application is the most common adopted approach. This kind of solution involves applying existing standards (e.g. CMSD) for data exchange between manufacturing applications and DES models, along with other tasks, such as distribution fitting, for instance. Thus, it can be stated that the fourth method usually involves the third method of Barlas and Heavey [30], this being the most used solution.

Regarding automatic generation of DES models, it is possible to see that $61 \%$ of the reviewed solutions considered some type of generators. Moreover, $73 \%$ of these generators 
addressed production system problems, being the most representative domain in the reviewed papers.

As discussed throughout this section, a proper answer to RQ2 must be divided in the recent developments in animation, automated data exchange and automatic model generation in DES. Regarding the former, it is interesting to note that, whilst all papers relevant for RQ1 regarded some kind of visualization features to be very important for DES in the I4.0 agenda, there is still some evidence suggesting that DES tool vendors [21] and even DES practitioners $[24,25]$ still are sceptical about the importance of animation in DES, in many different aspects. Regarding the application of VR technology in DES models, it is possible to see that some studies have already starting to report this evidence. In fact, some DES tool vendor are already incorporating this feature in their software, as is the case with Simio, for instance.

Lastly, concerning the automation of data input and the automatic generation of DES models, of the reviewed papers, most matched these features, with only $29 \%$ disregarding the later in favour of the former. Yet, as illustrated in Table III, the presented real-time simulators are all applicable to a single domain problem, with the majority modelling production lines systems of the manufacturing industry. In fact, 3 out of the 11 studies that presented DES model generators $(27 \%)$ addressed internal logistics problems, whilst the remaining focused on the production domain. This seems to indicate a high focus of researchers and practitioners in a single type of problem, possibly disregarding the remaining. In fact, it is interesting to note that, for instance external logistics - a crucial problem for supply chains of organizations, which is highlighted in [2] - was not addressed by any of the considered papers in this review. It is also noteworthy that none of the reviewed studies addressed the modularity, as a way to automatically build simulation models and the ability to share the submodels between different generators. This had already been stated by Fowler and Rose [12] as a grand challenge in DES.

\section{SETTING A R\&D AGENDA FOR DES}

With the conclusion of the literature review focusing on the role of DES in I4.0, this section regards the authors' proposal of a possible list of items that are still not covered in literature, and thus compose a research and development agenda, in the scope of I4.0. In this regard, the following number (\#) of research and development agenda items can be withdrawn:

\section{- $R \& D$ Agenda Item \#1: DES as na instructive tool}

DES studies can be used to illustrate and demonstrate, through animation, the dynamics associated to business and processes of organizations. Moreover, these studies can be used as instructive tools, in order to increase the confidence level to a faster dissemination of these business and processes dynamics in industry. Nowadays, 3D animation in simulation is becoming increasingly adopted by available commercial tools and the advantages of this type of animation over the more traditional 2D animation are well-known. In fact, VR can further improve these benefits $[4,25]$. These instructive tools, armed with DES features, such as VR integration and the ability to test alternative scenarios, can have considerable advantages, especially in an I4.0 context, characterized by the dynamics of business and processes.

\section{- $R \& D$ Agenda Item \#2: Assessing the added-value of I4.0 through DES}

The benefits of DES in several problems in industry are well-known and the literature covering this is vast. In these studies, DES is used to quantify several key performance indicators. Furthermore, it is claimed that the implementation of I4.0 concepts in organizations leads to many benefits. Nevertheless, no study, to the best of the author's knowledge, has yet tried to use DES to precisely and accurately quantify the difference in added-value, before and after the implementation of I4.0, in the performance of an organization, or in a specific process. 
- R\&D Agenda Item \#3: Reusable submodels

In light of increasingly more complex problems and the need to reduce the modelling phase duration, modellers will need to pave the way to reduce the duration of this phase. As noted by Fowler and Rose [12], this can be achieved in one of two ways. The first consists in defining broad automatic simulation model generators to specific systems of specific companies, for instance. However, this would be a too tailored solution. An alternative would be to define broad simulation sub-models [45] that can then be used by less tailored generators. From the reviewed studies, it was noted that none tried to use this, to tackle the problem of generating simulation models, which could bring several benefits, such as the ability to reuse and share sub-models.

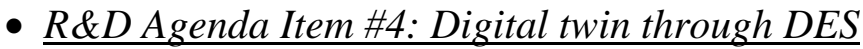

One of the aims of I4.0 is to reach the so-called digital twin, a real-time digital representation of the entire factory. DES can contribute to this aim, where automation of data exchange and automatic model generation are two essential features. Furthermore, these factory digital representations could be enhanced with the ability to test scenarios in real-time and other features that DES allows. One approach to do this could be related to the above R\&D item, i.e., to use reusable sub-models could constitute a model of a system, which, in its turn, could be linked to other models, forming the model of a factory. In any case, whatever the approach to do this may be, no studies regarding this issue were found.

\section{- $\underline{R} \& D$ Agenda Item \#5: Supply chain real-time simulation}

From the reviewed solutions, it was noted that mostly solutions for production lines problems were presented. Yet, other types of problems also required this feature. In fact, as indicated by Kagermann et al. [2], one of such types of problems is supply chains. Due to their high levels of uncertainty and variability, simulation seems to be the most effective technique to address these problems. Moreover, in the context of I4.0, the ability to visualize these complex networks, including internal logistics, as well as the ability to have real-time simulation models (both in automated data exchange and in automatic generation) of these systems is needed.

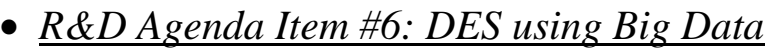

One of the consequences of the implementation of I4.0 is the Big Data sets being generated. These data have knowledge which needs to be extracted from raw data. To achieve this, DES alone, or coupled with other Big Data Analytics techniques can be of great importance. In this sense, real-time simulations can be essential. Despite this, no study was found coupling DES with Big Data Analytics.

\section{CONCLUSIONS}

Industry 4.0 (I4.0) aims to bring many innovative concepts, in order to achieve the "smart factory". In the scope I4.0, it becomes necessary to understand what are the types of problems in which Discrete-Event Simulation (DES) can be used that require further contributes, in order for DES to comply with the I4.0 agenda. Thus, this paper presented a literature review (LR) aiming to propose a research and development agenda for DES practitioners, in the scope of the I4.0 agenda. The LR consisted in answering two RQs by analysing 32 relevant papers.

The research method employed in this LR was different from traditional literature reviews, since the formulated research questions (RQ) could not be answered at the same time, i.e., only after answering RQ1 could search queries be defined to answer the second RQ. The authors chose this method, because the literature covering both DES and I4.0 is still reduced, thus, from available literature regarding RQ1, it was not possible to properly understand what are the current contributes of DES to I4.0. Because of this, RQ1 was used to extract what are 
the main expectations in which DES can contribute to I4.0. Only thereafter, could the review continue with RQ2, to understand what is the current status of these expectations.

Regarding RQ1, it was found that the main aspects in which DES is expected to contribute to I4.0 are: visualization, automation of data input and automatic DES model generation. In its turn, to answer RQ2, studies regarding these aspects were reviewed, which allowed the authors to identify some gaps, which allowed the formulation of a research and development agenda, including the following items: (i) studies that use DES as an instructive tool for the dynamics of processes; (ii) use DES to assess the added-value of I4.0 to processes of organizations; (iii) reusable sub-models; (iv) use DES to achieve the "digital twin" of factories; (v) use real-time DES to model today's supply chains, characterized by their uncertainty and variability; and (vi) couple DES with Big Data Analytics techniques in problems that use Big Data sets.

This paper contributes to literature with a review, which assessed the current status of DES in I4.0. In addition, DES practitioners also benefit from this paper with the proposed formulated research and development agenda. In the view of the authors, these items should be tackled by DES modellers, in order for DES to comply with the I4.0 agenda.

\section{ACKNOWLEDGEMENT}

This work has been supported by COMPETE: POCI-01-0145-FEDER-007043 and FCT - Fundação para a Ciência e Tecnologia within the Project Scope: UID/CEC/00319/2013 and by the Doctoral scholarship PDE/BDE/114566/2016 funded by FCT, the Portuguese Ministry of Science, Technology and Higher Education, through national funds, and co-financed by the European Social Fund (ESF) through the Operational Programme for Human Capital (POCH).

\section{REFERENCES}

[1] Lasi, H.; Fettke, P.; Kemper, H.-G.; Feld, T.; Hoffmann, M. (2014). Industry 4.0, Business \& Information Systems Engineering, Vol. 6, No. 4, 239-242, doi:10.1007/s12599-014-0334-4

[2] Kagermann, H.; Wahlster, W.; Helbig, J. (2013). Recommendations for implementing the strategic initiative Industrie 4.0: Securing the future of German manufacturing industry, Final report of the Industrie 4.0 Working Group, Forschungsunion, Frankfurt/Main

[3] Chong, L.; Ramakrishna, S.; Singh, S. (2018). A review of digital manufacturing-based hybrid additive manufacturing processes, The International Journal of Advanced Manufacturing Technology, Vol. 95, No 5-8, 2281-2300, doi:10.1007/s00170-017-1345-3

[4] Turner, C. J.; Hutabarat, W.; Oyekan, J.; Tiwari, A. (2016). Discrete event simulation and virtual reality use in industry: new opportunities and future trends, IEEE Transactions on HumanMachine Systems, Vol. 46, No. 6, 882-894, doi:10.1109/THMS.2016.2596099

[5] Tan, Y.; Takakuwa, S. (2011). Use of simulation in a factory for business continuity planning, International Journal of Simulation Modelling, Vol. 10, No. 1, 17-26, doi:10.2507/ IJSIMM10(1)2.172

[6] Seebacher, G.; Winkler, H.; Oberegger, B. (2015). In-plant logistics efficiency valuation using discrete event simulation, International Journal of Simulation Modelling, Vol. 14, No. 1, 60-70, doi:10.2507/IJSIMM14(1)6.289

[7] Wang, Y. R.; Chen, A. N. (2016). Production logistics simulation and optimization of industrial enterprise based on Flexsim, International Journal of Simulation Modelling, Vol. 15, No. 4, 732741, doi:10.2507/IJSIMM15(4)CO18

[8] Jahangirian, M.; Eldabi, T.; Naseer, A.; Stergioulas, L. K.; Young, T. (2010). Simulation in manufacturing and business: A review, European Journal of Operational Research, Vol. 203, No. 1, 1-13, doi:10.1016/j.ejor.2009.06.004

[9] Vieira, A. C.; Dias, L. S.; Pereira, G. A. B.; Oliveira, J. A.; Carvalho, M. S.; Martins, P. (2015). Using Simio to automatically create 3D warehouses and compare different storage strategies, FME Transactions, Vol. 43, No. 4, 335-343, doi:10.5937/fmet1504335V 
[10] Dias, L. M. S.; Pereira, G. A. B.; Vik, P.; Oliveira, J. A. (2014). Layout and process optimisation: using computer-aided design (CAD) and simulation through an integrated systems design tool, International Journal of Simulation and Process Modelling, Vol. 9, No. 1-2, 46-62, doi:10.1504/IJSPM.2014.061437

[11] Kirchhof, P. (2016). Automatically generating flow shop simulation models from SAP data, Proceedings of the 2016 Winter Simulation Conference, Industrial Case Studies, 3588-3589

[12] Fowler, J. W.; Rose, O. (2004). Grand challenges in modeling and simulation of complex manufacturing systems, Simulation, Vol. 80, No. 9, 469-476, doi:10.1177/0037549704044324

[13] Popovics, G.; Pfeiffer, A.; Monostori, L. (2016). Generic data structure and validation methodology for simulation of manufacturing systems, International Journal of Computer Integrated Manufacturing, Vol. 29, No. 12, 1272-1286, doi:10.1080/0951192X.2016.1187296

[14] Dias, L. M. S.; Vieira, A. A. C.; Pereira, G. A. B.; Oliveira, J. A. (2016). Discrete simulation software ranking - a top list of the worldwide most popular and used tools, Proceedings of the 2016 Winter Simulation Conference, 1060-1071, doi:10.1109/WSC.2016.7822165

[15] Abu-Taieh, E.; El Sheikh, A. (2007). Commercial simulation packages: a comparative study, International Journal of Simulation: Systems, Science \& Technology, Vol. 8, No. 2, 66-76

[16] Hlupic, V.; Paul, R. J. (1999). Guidelines for selection of manufacturing simulation software, IIE Transactions, Vol. 31, No. 1, 21-29, doi:10.1023/A:1007568516643

[17] Brettel, M.; Friederichsen, N.; Keller, M.; Rosenberg, M. (2014). How virtualization, decentralization and network building change the manufacturing landscape: An Industry 4.0 perspective, International Journal of Information and Communication Engineering, Vol. 8, No. $1,37-44$

[18] Posada, J.; Toro, C.; Barandiaran, I.; Oyarzun, D.; Stricker, D.; de Amicis, R.; Pinto, E. B.; Eisert, P.; Döllner, J.; Vallarino, I. (2015). Visual computing as a key enabling technology for Industrie 4.0 and industrial internet, IEEE Computer Graphics and Applications, Vol. 35, No. 2, 26-40, doi:10.1109/MCG.2015.45

[19] Ferro, R.; Ordóñez, R. E. C.; Anholon, R. (2017). Analysis of the integration between operations management manufacturing tools with discrete event simulation, Production Engineering, Vol. 11, No. 4-5, 467-476, doi: $10.1007 / \mathrm{s} 11740-017-0755-2$

[20] Akpan, I. J.; Shanker, M. (2017). The confirmed realities and myths about the benefits and costs of $3 \mathrm{D}$ visualization and virtual reality in discrete event modeling and simulation: A descriptive meta-analysis of evidence from research and practice, Computers \& Industrial Engineering, Vol. 112, 197-211, doi:10.1016/j.cie.2017.08.020

[21] Bijl, J. L.; Boer, C. A. (2011). Advanced 3D visualization for simulation using game technology, Proceedings of the 2011 Winter Simulation Conference, 2810-2821, doi:10.1109/ WSC.2011.6147985

[22] Robinson, S. (2005). Discrete-event simulation: from the pioneers to the present, what next?, Journal of the Operational Research Society, Vol. 56, No. 6, 619-629, doi:10.1057/ palgrave.jors. 2601864

[23] Hollocks, B. W. (2006). Forty years of discrete-event simulation - a personal reflection, Journal of the Operational Research Society, Vol. 57, No. 12, 1383-1399, doi:10.1057/ palgrave.jors. 2602128

[24] Akpan, I. J.; Brooks, R. J. (2012). Users' perceptions of the relative costs and benefits of 2D and 3D visual displays in discrete-event simulation, Simulation, Vol. 88, No. 4, 464-480, doi: $10.1177 / 0037549711423734$

[25] Akpan, I. J.; Brooks, R. J. (2014). Experimental evaluation of user performance on twodimensional and three-dimensional perspective displays in discrete-event simulation, Decision Support Systems, Vol. 64, 14-30, doi:10.1016/j.dss.2014.04.002

[26] Ghani, U.; Monfared, R.; Harrison, R. (2015). Integration approach to virtual-driven discrete event simulation for manufacturing systems, International Journal of Computer Integrated Manufacturing, Vol. 28, No. 8, 844-860, doi:10.1080/0951192X.2014.924159

[27] Petti, A.; Hutabarat, W.; Oyekan, J.; Turner, C.; Tiwari, A.; Prajapat, N.; Gan, X.-P.; Ince, N. (2016). Impact of model fidelity in factory layout assessment using immersive discrete event simulation, Proceedings of the $8^{\text {th }}$ Operational Research Society Simulation Workshop, 124-134 
[28] Oyekan, J.; Hutabarat, W.; Turner, C.; Tiwari, A.; Prajapat, N.; Ince, N.; Gan, X.-P.; Waller, T. (2015). A 3D immersive discrete event simulator for enabling prototyping of factory layouts, Procedia CIRP, Vol. 38, 63-67, doi:10.1016/j.procir.2015.08.043

[29] Skoogh, A.; Perera, T.; Johansson, B. (2012). Input data management in simulation - Industrial practices and future trends, Simulation Modelling Practice and Theory, Vol. 29, 181-192, doi:10.1016/j.simpat.2012.07.009

[30] Barlas, P.; Heavey, C. (2016). Automation of input data to discrete event simulation for manufacturing: A review, International Journal of Modeling, Simulation, and Scientific Computing, Vol. 7, No. 1, Paper 1630001, doi:10.1142/S1793962316300016

[31] Rodriguez, C. (2015). User interface to automate the collection and processing of data for discrete event simulation projects, IEEE Science and Information Conference, 525-532, doi:10.1109/SAI.2015.7237193

[32] Vieira, A. C.; Dias, L. S.; Pereira, G. B.; Oliveira, J. A.; Carvalho, M. S.; Martins, P. (2016). Automatic simulation models generation of warehouses with milkruns and pickers, Proceedings of the $28^{\text {th }}$ European Modelling and Simulation Symposium, 231-241

[33] Krenczyk, D. (2014). Automatic generation method of simulation model for production planning and simulation systems integration, Advanced Materials Research, Vol. 1036, 825-829, doi:10.4028/www.scientific.net/AMR.1036.825

[34] Robertson, N.; Perera, T. (2002). Automated data collection for simulation?, Simulation Practice and Theory, Vol. 9, No. 6-8, 349-364, doi:10.1016/S0928-4869(01)00055-6

[35] Robertson, N. H.; Perera, T. (2001). Feasibility for automatic data collection, Proceedings of the 2001 Winter Simulation Conference, Vol. 2, 984-990, doi:10.1109/WSC.2001.977403

[36] Barlas, P.; Heavey, C.; Dagkakis, G. (2015). An open source tool for automated input data in simulation, International Journal of Simulation Modelling, Vol 14, No 4, 596-608, doi:10.2507/IJSIMM14(4)3.306

[37] Popovics, G.; Pfeiffer, A.; Kádár, B.; Vén, Z.; Kemény, L.; Monostori, L. (2012). Automatic simulation model generation based on PLC codes and MES stored data, Procedia CIRP, Vol. 3, 67-72, doi:10.1016/j.procir.2012.07.013

[38] Popovics, G.; Kardos, C.; Pfeiffer, A.; Kadar, B.; Vén, Z.; Monostori, L. (2012). Automatic simulation model generation supported by data stored in low level controllers, IFAC Proceedings Volumes, Vol. 45, No. 6, 242-247, doi:10.3182/20120523-3-RO-2023.00352

[39] Popovics, G.; Monostori, L. (2013). ISA standard simulation model generation supported by data stored in low level controllers, Procedia CIRP, Vol. 12, 432-437, doi:10.1016/ j.procir.2013.09.074

[40] Skoogh, A.; Johansson, B.; Stahre, J. (2012). Automated input data management: evaluation of a concept for reduced time consumption in discrete event simulation, Simulation, Vol. 88, No. 11, 1279-1293, doi:10.1177/0037549712443404

[41] Barlas, P.; Heavey, C. (2014). Towards automated simulation input data, Proceedings of the Operational Research Society Simulation Workshop (SW14), 10 pages

[42] Haraszkó, C.; Németh, I. (2015). DES configurators for rapid virtual prototyping and optimisation of manufacturing systems, Periodica Polytechnica Mechanical Engineering, Vol. 59, No. 3, 143-152, doi:10.3311/PPme.7888

[43] Lee, Y.-T. T.; Riddick, F. H.; Johansson, B. J. I. (2011). Core manufacturing simulation data - a manufacturing simulation integration standard: overview and case studies, International Journal of Computer Integrated Manufacturing, Vol. 24, No. 8, 689-709, doi:10.1080/ 0951192X.2011.574154

[44] Bloomfield, R.; Mazhari, E.; Hawkins, J.; Son, Y.-J. (2012). Interoperability of manufacturing applications using the Core Manufacturing Simulation Data (CMSD) standard information model, Computers \& Industrial Engineering, Vol. 62, No. 4, 1065-1079, doi:10.1016/j.cie.2011.12.034

[45] Robinson, S.; Nance, R. E.; Paul, R. J.; Pidd, M.; Taylor, S. J. E. (2004). Simulation model reuse: definitions, benefits and obstacles, Simulation Modelling Practice and Theory, Vol. 12, No. 7-8, 479-494, doi: $\underline{10.1016 / \mathrm{j} . \text { simpat.2003.11.006 }}$ 